\title{
Corrigendum
}

\section{Corrigendum to "Model assessment of present-day Phaeocystis colony blooms in the Southern Bight of the North Sea (SBNS) by comparison with a reconstructed pristine situation" [Harmful Algae 37 (2014) \\ $172-182]$}

Christiane Lancelot ${ }^{\mathrm{a}, *}$, Paul Passy ${ }^{\mathrm{b}}$, Nathalie Gypens ${ }^{\mathrm{a}}$

${ }^{a}$ Université Libre de Bruxelles, Ecologie des Systèmes Aquatiques, Boulevard du Triomphe, CP 221, B-1050 Brussels, Belgium

${ }^{\mathrm{b}}$ FR3020, UPMC E CNRS, Fédération Île-de-France de Recherche sur l'Environnement Université Pierre et Marie Curie, 4 place Jussieu, 75005 Paris, France

The authors regret that parts A and B of Fig. 7 in the above published paper were incorrect. The correct version of Fig. 7 is given below: The authors would like to apologise for any inconvenience caused.
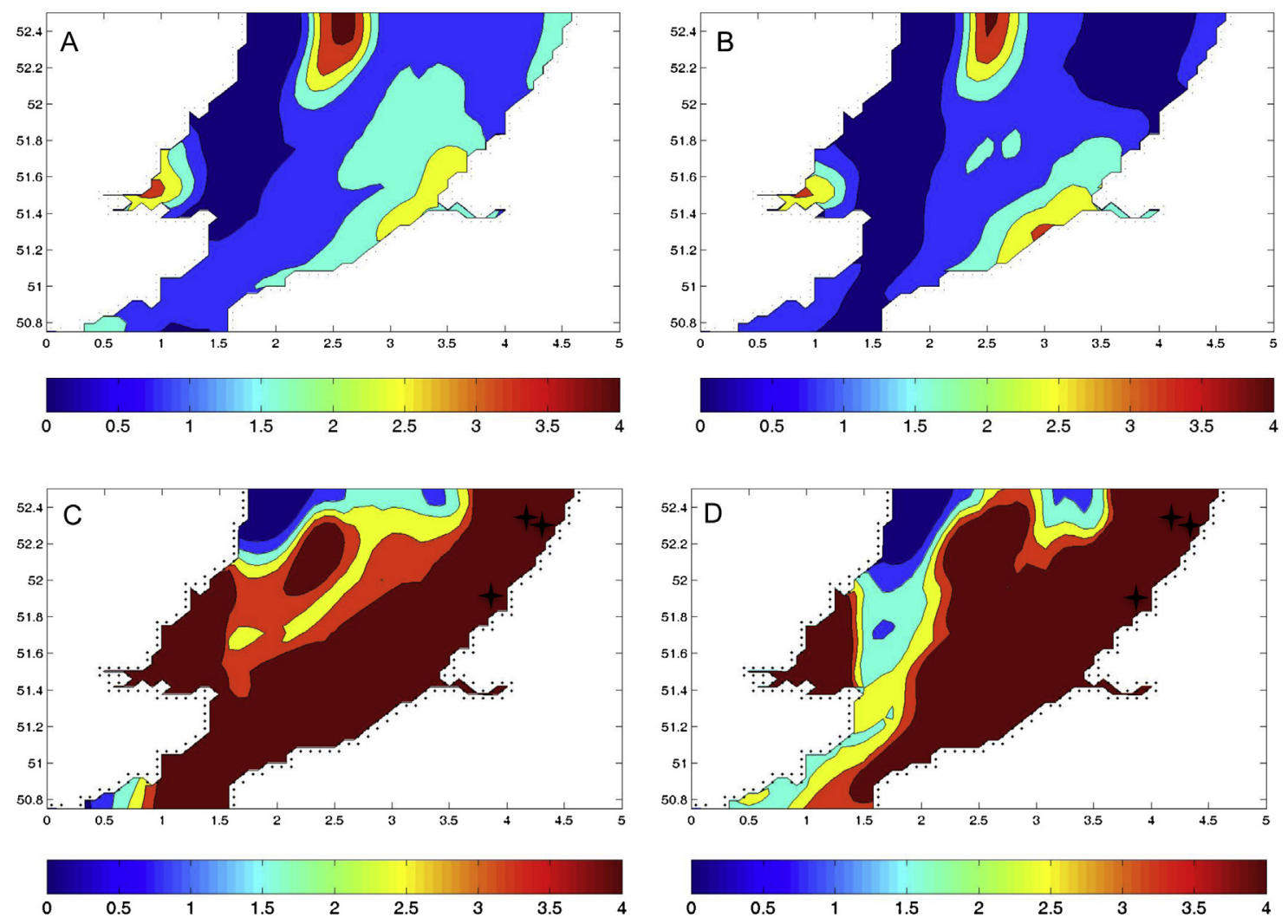

Fig. 7.

\footnotetext{
DOI of original article: http://dx.doi.org/10.1016/j.hal.2014.05.017

* Corresponding author. Tel.: +32 26505988; fax: +32 26505993.

E-mail address: lancelot@ulb.ac.be (C. Lancelot).
} 